\title{
Exigência de Lisina, com Base no Conceito de Proteína Ideal, para Suínos Machos Castrados de Dois Grupos Genéticos, na Fase de Crescimento ${ }^{1}$
}

\section{Luiz Fernando Gasparotto², Ivan Moreira ${ }^{3}$, Antonio Cláudio Furlan³, Elias Nunes Martins³, Maurício Marcos Júnior ${ }^{4}$}

RESUMO - Foi conduzido um experimento para determinar as exigências de lisina para suínos machos castrados, de dois diferentes grupos genéticos na fase de crescimento, com base no conceito de proteína ideal. Foram utilizados 16 suínos do grupo genético comum (GGC) e 16 suínos do grupo genético melhorado (GGM), distribuídos em um delineamento de blocos ao acaso, com quatro tratamentos, duas repetições e dois animais por baia. Os tratamentos consistiram de uma ração referência, à base de milho e farelo de soja, contendo $0,75 \%$ de lisina e outras três rações, acrescentando-se níveis crescentes de lisina para se obter 0,90, 1,05 e 1,20\% de lisina total na ração. Adicionou-se aminoácidos sintéticos (L-lisina HCl, DL-metionina, L-treonina e L-triptofano) para manter os níveis de aminoácidos, de acordo com o perfil de proteína ideal. Para o GGC (20 a $50 \mathrm{~kg}$ de peso vivo), as variáveis, consumo de ração diário (CRD), ganho de peso diário (GPD) e conversão alimentar (CA) não sofreram efeito dos níveis de lisina (NL). Observou-se efeito quadrático dos NL sobre o CRD e GPD para o GGM (24 a 45 kg de PV) de 0 a 14 e de 0 a 18 dias, mas não no período total de experimento. Não houve diferença entre GGC e GGM para a variável nitrogênio da uréia plasmática. A exigência de lisina total, baseado no conceito de proteína ideal, para suínos machos castrados do GGM (24 a $45 \mathrm{~kg}$ de peso vivo) é de 1,00\%, enquanto que para GGC (20 a $50 \mathrm{~kg}$ de peso vivo) é de $0,75 \%$.

Palavras-chave: aminoácido, características de carcaça, desempenho, nitrogênio da uréia plasmática

\section{Lysine Requirement Based on Ideal Protein Concept, for Growing Barrows from Two Genetic Groups}

\begin{abstract}
A trial was carried out to determine the lysine requirements for barrows during growing phase from two genetic pig groups according to the ideal protein concept. Sixteen animals from genetic common group (GCG) were used and other sixteen ones, from the genetic improved group (GIG) were allotted in a randomized block design with four treatments two replicates and two pigs per pen. The treatments constituted of the basal diet, based on corn-soybean meal containing $0.75 \%$ of lysine and other three diets, adding increasing lysine levels to get $0.90 ; 1.05$ and $1.20 \%$ of total lysine on diet. Synthetic amino acids (L-lysine HCl, DL-methionine, L threonine and Ltryptophan) were added to keep amino acid levels according to the ideal protein profile. For GCG (20 to $50 \mathrm{~kg}$ of live weight), lysine levels (LL) did not affect daily feed intake (DFI), daily weight gain (DWG) and feed conversion (FC). It was observed a quadratic effect of LL on DFI and DGW in GIG (24 to $45 \mathrm{~kg}$ of live weight), from 0 to 14 and from 0 to 18 days, but not through total period. There was no difference between GCG and GIG for plasma urea nitrogen (PUN). The total lysine requirement, based on ideal protein concept, of castrated growing pigs for GIG (24 to $45 \mathrm{~kg}$ of live weight) is $1.00 \%$, while for GCG (20 to $50 \mathrm{~kg}$ of live weight) is $0.75 \%$.
\end{abstract}

Key Words: amino acid, carcass traits, performance, plasma urea nitrogen

\section{Introdução}

Durante muitos anos, as dietas de suínos foram formuladas com base na proteína bruta. Com o aumento da disponibilidade dos aminoácidos sintéticos no mercado e por necessidades econômicas e ambientais, os nutricionistas têm procurado formular as rações de acordo com as exigências nutricionais dos suínos, considerando aminoácidos limitantes específicos.

Muitos estudos têm sido conduzidos para determinar as exigências de aminoácidos para suínos e este processo tem sido laborioso e lento e, ainda, não há determinações exatas das exigências da maioria dos aminoácidos necessários para os vários estágios de crescimento e ganho de peso corporal. As dietas práticas de suínos contêm considerável excesso de outros aminoácidos essenciais (PARSONS e BAKER, 1994). O excesso de aminoácidos na dieta representa um gasto de energia para sua metabolização, implicando em aumento do custo de produção.

De acordo com COMA e ZIMMERMAN (1993), o nitrogênio da uréia plasmática (NUP) pode ser

\footnotetext{
${ }^{1}$ Parte da dissertação de mestrado do primeiro autor, parcialmente financiado pelo CNPq e pela Ajinomoto.

${ }^{2}$ Aluno do curso de Mestrado em Zootecnia da UEM.

3Professores do DZO/UEM. E.mail: imoreira@uem.br; acfurlan@uem.br; enmartins@uem.br

${ }^{4}$ Aluno do curso de Zootecnia, bolsista de Iniciação Científica - IC/CNPq.
} 
usado como um indicador da máxima utilização de aminoácidos. Desse modo, o aumento do NUP pode indicar ineficiência na utilização de aminoácidos, sugerindo uma exigência de lisina adequado, baseado na excreção mínima de nitrogênio na uréia.

A aplicação do modelo de proteína ideal, seguido de um ótimo desempenho de crescimento, pode servir como um processo para redução da excreção de nitrogênio na produção de suínos, e o uso de modelos de aminoácidos tem sido o caminho mais preciso para estabelecer as exigências de nutrientes (GOMES et al., 1998).

Em função da proteína dietética poder suprir os nutrientes (aminoácidos) para a formação de tecido magro, bem como para reposição de pêlo, pele, enzimas e várias células que são perdidas no metabolismo celular em todos os órgãos, poderia se pensar em fornecer uma proteína ideal para cada função fisiológica do animal (VAN LUNEN, 1995).

Considerando-se que existem diferenças no consumo, na taxa e eficiência de crescimento entre as categorias animais (HANSEN e LEWIS, 1993), e ainda, que a lisina é um aminoácido limitante em dietas de suínos (YEN et al., 1986), existe a necessidade de que a exigência nutricional deste aminoácido seja estabelecida por categoria animal.

A capacidade de deposição de proteína é influenciada pela genótipo, sexo, meio ambiente, estado de saúde e ingestão de energia, sugerindo que estes fatores precisam ser considerados na formulação da dieta, para suínos em crescimento (FRIESEN et al., 1996). Por outro lado, suínos com genótipos superiores requerem mais proteína e aminoácido na dieta para suportar alta taxa de deposição de proteína, em relação a suínos de genótipos inferiores (CAMPBELL e TAVERNER 1988).

Por esta razão, são encontradas diversas recomendações de exigência de lisina para suínos em crescimento. DONZELE et al. (1994ab) indicaram 0,89 e 0,91\% para machos inteiros e fêmeas, respectivamente, Por outro lado, FERREIRA et al. (1996), em revisão da literatura brasileira, concluíram por $0,85 \%$, enquanto BENATI (1996), compilando dados de dez empresas que atuam no mercado brasileiro, encontrou, como média nas rações de crescimento, $0,93 \%$ de lisina total. Por sua vez, o NRC (1998) recomenda 0,95\% de lisina para suínos de 20 a $50 \mathrm{~kg}$ de peso vivo.

Assim, entendeu-se ser necessário determinar a exigência de lisina, com base no conceito de proteína ideal, para suínos machos castrados em crescimento, de dois grupos genéticos.

\section{Material e Métodos}

O experimento foi conduzido, no período de 18 de maio a 24 de junho de 1998 , sendo que as médias de temperatura mínima e máxima foram 13,8 e $25,8^{\circ} \mathrm{C}$, respectivamente. Os animais foram alojados em um galpão de alvenaria, coberto com telhas de fibrocimento, dividido em duas alas, sendo as mesmas divididas em oito baias $\left(7,60 \mathrm{~m}^{2}\right.$ cada), separadas por um corredor central. Cada baia possuía um comedouro semi-automático de duas bocas localizado na parte frontal e dois bebedouros do tipo chupeta no fundo da baia.

Foram utilizados 32 suínos, de dois grupos genéticos diferentes, sendo 16 machos castrados "comuns" (Landrace x Large White x Duroc), com peso médio inicial de 19,5 kg, e 16 machos castrados de elevada produção de carne magra (Agroceres PIC C15 x Ag 400 e C 15 x Ag 405) com peso médio inicial de $24,2 \mathrm{~kg}$.

O delineamento experimental utilizado foi o de blocos ao acaso, em esquema fatorial 4x2 (quatro níveis de lisina e dois grupos genéticos) e duas repetições. A unidade experimental foi composta de dois animais por baia. O parentesco e o peso inicial dos leitões foram considerados para a formação das unidades experimentais.

Os tratamentos consistiram de uma ração referência (Tabela 1), à base de milho e farelo de soja, contendo $0,75 \%$ de lisina total e outras três rações, onde foram adicionados aminoácidos sintéticos (Llisina $\mathrm{HCl}$, DL-metionina, L-treonina e L-triptofano), para manter os níveis crescentes de aminoácidos $(0,90,1,05$ e $1,20 \%$ de lisina total $)$, de acordo com o perfil de proteína ideal indicado por BAKER (1996). Da mesma forma, os demais aminoácidos sintéticos foram adicionados para manter constante a relação aminoácido/lisina. A adição dos aminoácidos foi em substituição ao amido do milho. As composições centesimal, química e energética das rações experimentais utilizadas são apresentadas nas Tabelas 1 e 2 .

Foram realizadas análises de proteína bruta (PB), cálcio $(\mathrm{Ca})$ e fósforo $(\mathrm{P})$ das dietas (Tabela 2), de acordo com as técnicas descritas em SILVA (1990).

Os suínos receberam água e ração farelada à vontade, durante todo o período experimental.

Foram realizadas as pesagens dos animais e consumo de ração, aos 14, 28 e 37 dias de avaliação, após o inicio do período experimental. Após as pesagens dos animais, foram realizadas as coletas do sangue, atra- 
Tabela 1 - Composição (\%) das rações, contendo níveis crescentes de lisina, fornecidas aos suínos na fase de crescimento

Table 1 - Composition (\%) of diets containing increasing lysine levels, fed to growing pigs

\begin{tabular}{|c|c|c|c|c|}
\hline \multirow[t]{2}{*}{$\begin{array}{l}\text { Ingredientes } \\
\text { Ingredients }\end{array}$} & \multicolumn{4}{|c|}{$\begin{array}{c}\text { Níveis de lisina, \% } \\
\text { Lysine levels }\end{array}$} \\
\hline & 0,75 & 0,90 & 1,05 & 1,20 \\
\hline Farelo de soja & 12,19 & 12,19 & 12,19 & 12,19 \\
\hline $\begin{array}{l}\text { Soybean meal } \\
\text { Milho } \\
\text { Corn }\end{array}$ & 81,23 & 81,23 & 81,23 & 81,23 \\
\hline $\begin{array}{l}\text { Amido de milho } \\
\text { Corn starch }\end{array}$ & 2,500 & 2,094 & 1,678 & 1,262 \\
\hline $\begin{array}{l}\text { Fosfato bicálcico } \\
\text { Dicalcium phosphate }\end{array}$ & 1,812 & 1,812 & 1,812 & 1,812 \\
\hline $\begin{array}{l}\text { Calcário } \\
\text { Limestone }\end{array}$ & 0,828 & 0,828 & 0,828 & 0,828 \\
\hline $\begin{array}{l}\text { Sal comum } \\
\text { Salt }\end{array}$ & 0,400 & 0,400 & 0,400 & 0,400 \\
\hline $\begin{array}{l}\text { Tylan-S100 } \\
\text { Tylan-S100 }\end{array}$ & 0,100 & 0,100 & 0,100 & 0,100 \\
\hline $\begin{array}{l}\text { Suplemen. Vitamínico } \\
\text { Vitamin premix }\end{array}$ & 0,300 & 0,300 & 0,300 & 0,300 \\
\hline $\begin{array}{l}\text { Suplemento mineral } \\
\text { Mineral premix }\end{array}$ & 0,200 & 0,200 & 0,200 & 0,200 \\
\hline $\begin{array}{l}\text { DL-metionina, }(99,0 \%) \\
\text { DL-Methionine }\end{array}$ & 0,069 & 0,160 & 0,251 & 0,342 \\
\hline $\begin{array}{l}\text { L-lisina } \mathrm{HCl},(98,5 \%) \\
\text { L-Lysine }\end{array}$ & 0,292 & 0,485 & 0,677 & 0,869 \\
\hline $\begin{array}{l}\text { L-treonina, }(98,5 \%) \\
\text { L-Threonine }\end{array}$ & 0,085 & 0,187 & 0,289 & 0,391 \\
\hline $\begin{array}{l}\text { L-triptofano, }(98,5 \%) \\
\text { L-Tryptophan }\end{array}$ & 0,000 & 0,020 & 0,051 & 0,082 \\
\hline
\end{tabular}

1 Suplemento vitamínico. Composição porkg do produto (Vitamin mix to provide per $\mathrm{kg}$ of premix): Ác. fólico (Folic acid) - 167,0 mg; Vit. A 2.330.000 UI; B.H.T.- 32,7000 mg; Selênio (Selenium) - 66,7 mg; Avoparcin (Avoparcin) - 3.340,0 mg; Colina (Choline) - 43.300,0 mg; Ác. pantotênico (Pantothenic acid) - 2.667,0 mg; Ác. nicotínico (Nicotinic acid) - 5.567,0 mg; Vit. $B_{12}-66.700,0$ mcg; Vit. $B_{6}-667,0 \mathrm{mg}$; Vit. $B_{2}$ - 1000,0 mg; Vit. $B_{1}$ - 234,00 mg; Vit. $K_{3}-667,0$ mg; Vit. E - 5000 Ul; Vit. $\mathrm{D}_{3}-833.000 \mathrm{UI}$; Biotina (Biotine) - 25,0 mg; Veículo q.s.p. (Vehicle q.s.p.) - 1000,0 g.

2 Suplemento mineral. Composição porkg do produto (Mineral mix to provide per kg of premix): Co - 500,0 mg; Cu - 87.500,0 mg; Zn - 50.000,0 mg; Fe $-50.000,0 \mathrm{mg}$; Mn - 20.000,0 mg; I - 750,0 mg Vehicle q.s.p. (Vehicle q.s.p.) $-1000,0 \mathrm{~g}$.

vés de punção na veia cava cranial, os quais foram centrifugados a $3000 \mathrm{rpm}$, durante 15 minutos para a obtenção do plasma. Para a determinação das concentrações de nitrogênio da uréia plasmática (NUP) foi utilizado o processo enzimático (Kit comercial).

Após a pesagem aos 37 dias de experimento, foram feitas as medições de características de carcaça in vivo, efetuando-se medidas de espessura de toucinho na altura da primeira costela $\left(\mathrm{ETP}_{1}\right)$, espessura de toucinho na altura da última costela $\left(\mathrm{ETP}_{2}\right)$, espessura de toucinho na altura da última
Tabela 2 - Composição química e energética das rações contendo níveis crescentes de lisina, fornecidas aos suínos na fase de crescimento

Table 2 - Chemical and energetic composition of diets containing increasing lysine levels, fed to growing pigs

\begin{tabular}{|c|c|c|c|c|}
\hline \multirow[t]{2}{*}{$\begin{array}{l}\text { Ingredientes } \\
\text { Ingredients }\end{array}$} & \multicolumn{4}{|c|}{$\begin{array}{c}\text { Níveis de lisina, \% } \\
\text { Lysine levels }\end{array}$} \\
\hline & 0,75 & 0,90 & 1,05 & 1,20 \\
\hline \multicolumn{5}{|l|}{ Valores calculados 1} \\
\hline $\begin{array}{l}\text { Calculated values } 1 \\
\text { Proteína bruta, } \% \\
\text { Crude protein }\end{array}$ & 12,72 & 12,89 & 13,06 & 13,24 \\
\hline $\begin{array}{l}\text { Energia dig., } \mathrm{kcal} / \mathrm{kg} \\
\text { Digestible energy }\end{array}$ & 3337 & 3340 & 3344 & 3347 \\
\hline $\mathrm{Ca}, \%$ & 0,80 & 0,80 & 0,80 & 0,80 \\
\hline Fósforo total, \% & 0,62 & 0,62 & 0,62 & 0,62 \\
\hline $\begin{array}{l}\text { Total phosphorus } \\
\text { Lisina, \% }\end{array}$ & 0,75 & 0,90 & 1,05 & 1,20 \\
\hline $\begin{array}{l}\text { Lysine } \\
\text { Met.+ Cis., \% } \\
\text { Methionine + Cystine }\end{array}$ & 0,47 & 0,56 & 0,65 & 0,74 \\
\hline $\begin{array}{l}\text { Treonina, \% } \\
\text { Threonine, \% }\end{array}$ & 0,50 & 0,60 & 0,70 & 0,80 \\
\hline $\begin{array}{l}\text { Triptofano, } \% \\
\text { Tryptophan }\end{array}$ & 0,14 & 0,16 & 0,19 & 0,22 \\
\hline \multicolumn{5}{|l|}{$\begin{array}{l}\text { Valores analisados } \\
\text { Analyzed values }\end{array}$} \\
\hline $\begin{array}{l}\text { Proteína bruta, \% } \\
\text { Crude protein }\end{array}$ & 12,32 & 12,57 & 13,37 & 13,14 \\
\hline $\mathrm{Ca}, \%$ & 0,77 & 0,78 & 0,76 & 0,77 \\
\hline Fósforo total, \% & 0,53 & 0,53 & 0,56 & 0,54 \\
\hline
\end{tabular}

${ }^{1}$ Valores calculados com base na tabela da EMBRAPA (1991).

${ }^{1}$ Calculated values based on EMBRAPA table (1991).

vértebra lombar $\left(\mathrm{ETP}_{3}\right)$, e profundidade de lombo na altura da última costela (PL), utilizando um aparelho de ultra-som.

As variáveis estudadas foram submetidas à análise de variância de acordo com o modelo estatístico:

$$
\mathrm{Y}_{\mathrm{ijk}}=\mu+\mathrm{N}_{\mathrm{i}}+\mathrm{G}_{\mathrm{j}}+\mathrm{B}_{\mathrm{k}}+\mathrm{e}_{\mathrm{ijk}}
$$

em que: $\mathrm{Y}_{i j k}=$ variável estudada; $\mu=$ média geral; $\mathrm{N}_{\mathrm{i}}=$ efeito do nível de lisina $i,(i=0,75 ; 0,90 ; 1,05 ; \mathrm{e}$ $1,20 \%) ; \mathrm{G}_{\mathrm{j}}=$ efeito do grupo genético $j(1=$ comum, $2=$ melhorado); $\mathrm{B}_{\mathrm{k}}=$ efeito do bloco $k(k=1$ e 2$) ;$ $\mathrm{e}_{\mathrm{ijk}}=$ erro aleatório associado a cada observação. 
Os graus de liberdade referentes aos níveis de lisina nas rações foram desdobrados em polinômios. Para as variáveis que apresentaram efeito quadrático, foram feitas as derivações das equações, para obtenção do melhor nível de lisina.

\section{Resultados e Discussão}

Na Tabela 3 é apresentada a composição em aminoácidos, das rações experimentais.

Os resultados de consumo de ração diário (CRD), ganho de peso diário (GPD), conversão alimentar (CA) e consumo de lisina (CL), em função dos níveis de lisina nos períodos 0-14,0-28 e 0-37 dias de avaliação, na fase de crescimento, para os dois grupos genéticos, são apresentados na Tabela 4 .

No grupo genético comum (GGC), as variáveis CRD, GPD e CA não sofreram efeito $(\mathrm{P}>0,05)$ dos níveis de lisina nos períodos de 0-14, 0-28 e 0-37 dias de avaliação.

A ausência de efeitos dos níveis de lisina sobre consumo alimentar para os animais do GGC, observada neste trabalho, esta de acordo com resultados obtidos por diversos autores (CROMWELL et al., 1993; DONZELE et al., 1994a; FRIESEN et al., 1994; HAHN et al., 1995). Da mesma forma, EDMONDS e BAKER (1987) relataram que os suínos podem tolerar consideráveis excessos de aminoácidos, principalmente lisina, sem apresentar variações significativas no consumo alimentar e no ganho de peso. BAKER (1993) comentou ainda que nível de até $4 \%$ de lisina na dieta é bem tolerado pelos suínos.

No grupo genético melhorado (GGM), observouse efeito quadrático $(\mathrm{P}<0,05)$ dos níveis de lisina sobre o CRD no período de 0-14 dias de avaliação e peso vivo médio de 24,2 a $34,5 \mathrm{~kg}$, quando maior consumo seria atingido quando a dieta contivesse $0,95 \%$ de lisina, de acordo com a equação $\mathrm{Y}=-2,179129+8,112984 \mathrm{X}-4,27777 \mathrm{X}^{2}\left(\mathrm{R}^{2}=0,52\right)$. Este valor foi semelhante à aquele citado por GOODBAND et al. (1994), para suínos com peso vivo de 23 a $36 \mathrm{~kg}$, de médio ganho de carne criados no inverno. Da mesma forma, para o período de 0-28 dias, observou-se comportamento quadrático $(\mathrm{P}<0,06)$, em que o maior consumo seria obtido quando a dieta contivesse $0,95 \%$ lisina, segundo a equação $\mathrm{Y}=$ $2,64085+9,50149 X-5,016665 X^{2}\left(R^{2}=0,48\right)$.

Observou-se efeito quadrático $(\mathrm{P}<0,05)$ dos níveis de lisina sobre o GPD, para os animais do GGM, no período de 0-14 dias de avaliação, quando o GPD
Tabela 3 - Composição em aminoácidos das rações fornecidas aos suínos na fase de crescimento ${\text { (valores na matéria natural })^{1}}^{1}$

Table 3 - Amino acid composition of diets fed to growing pigs (asfed basis) ${ }^{1}$

\begin{tabular}{|c|c|c|c|c|}
\hline \multirow[t]{2}{*}{$\begin{array}{l}\text { Aminoácidos } \\
\text { Amino acids }\end{array}$} & \multicolumn{4}{|c|}{$\begin{array}{c}\text { Níveis de lisina, \% } \\
\text { Lysine levels }\end{array}$} \\
\hline & 0,75 & 0,90 & 1,05 & 1,20 \\
\hline \multicolumn{5}{|l|}{ Essenciais } \\
\hline $\begin{array}{l}\text { Essential } \\
\text { Arginina, \% }\end{array}$ & 0,80 & 0,70 & 0,75 & 0,72 \\
\hline $\begin{array}{l}\text { Arginine } \\
\text { Histidina, \% } \\
\text { Histidine }\end{array}$ & 0,38 & 0,34 & 0,35 & 0,34 \\
\hline $\begin{array}{l}\text { Isoleucina, \% } \\
\text { Isoleucine }\end{array}$ & 0,52 & 0,49 & 0,51 & 0,50 \\
\hline $\begin{array}{l}\text { Leucina, } \% \\
\text { Leucine }\end{array}$ & 1,29 & 1,30 & 1,27 & 1,26 \\
\hline $\begin{array}{l}\text { Lisina, \% } \\
\text { Lysine }\end{array}$ & 0,82 & 0,89 & 1,11 & 1,25 \\
\hline $\begin{array}{l}\text { Metionina, \% } \\
\text { Methionine }\end{array}$ & 0,31 & 0,35 & 0,45 & 0,51 \\
\hline $\begin{array}{l}\text { Fenilalanina, \% } \\
\text { Phenylalanine }\end{array}$ & 0,65 & 0,63 & 0,64 & 0,62 \\
\hline $\begin{array}{l}\text { Treonina, } \% \\
\text { Threonine }\end{array}$ & 0,59 & 0,60 & 0,74 & 0,82 \\
\hline $\begin{array}{l}\text { Triptofano, } \% \\
\text { Tryptophan }\end{array}$ & 0,13 & 0,14 & 0,17 & 0,20 \\
\hline $\begin{array}{l}\text { Valina, } \% \\
\text { Valine }\end{array}$ & 0,66 & 0,62 & 0,63 & 0,62 \\
\hline \multicolumn{5}{|l|}{$\begin{array}{l}\text { Não-essenciais } \\
\text { Nonessential }\end{array}$} \\
\hline $\begin{array}{l}\text { Alanina, \% } \\
\text { Alanine }\end{array}$ & 0,79 & 0,78 & 0,75 & 0,76 \\
\hline $\begin{array}{l}\text { Ácido aspártico, \% } \\
\text { Aspartic acid }\end{array}$ & 1,23 & 1,11 & 1,15 & 1,11 \\
\hline $\begin{array}{l}\text { Ácido glutâmico, \% } \\
\text { Glutamic acid }\end{array}$ & 2,44 & 2,32 & 2,33 & 2,30 \\
\hline $\begin{array}{l}\text { Cistina, } \% \\
\text { Cystine }\end{array}$ & 0,25 & 0,24 & 0,23 & 0,23 \\
\hline $\begin{array}{l}\text { Glicina, \% } \\
\text { Glycine }\end{array}$ & 0,56 & 0,51 & 0,53 & 0,52 \\
\hline $\begin{array}{l}\text { Serina, \% } \\
\text { Serine }\end{array}$ & 0,66 & 0,62 & 0,63 & 0,62 \\
\hline $\begin{array}{l}\text { Tirosina, \% } \\
\text { Tyrosine }\end{array}$ & 0,35 & 0,34 & 0,36 & 0,36 \\
\hline
\end{tabular}

${ }^{1}$ Análises realizadas nos laboratórios da Ajinomoto - Biolatina Indústria e Comércio Ltda.

${ }^{1}$ Analyzed by Ajonomoto - Biolatina Indústria e Comércio Ltda.

máximo seria obtido quando a dieta contivesse $0,96 \%$ de lisina, segundo a equação $Y=-2,411674+6,66531 X$ $-3,48888 \mathrm{X}^{2},\left(\mathrm{R}^{2}=0,72\right)$ e efeito quadrático $(\mathrm{P}<0,06)$ no período 0-28 dias de avaliação, ocorrendo maior GPD para o nível de $0,95 \%$ de lisina, de acordo com aequação $Y=-1,12865+4,07532 X-2,15555 X^{2}\left(R^{2}=0,68\right)$. No período de 0-37 dias de avaliação, não se obser- 
Tabela 4 - Consumo de ração diário (CRD), ganho de peso diário (GPD), conversão alimentar (CA) e consumo de lisina (CL) nos períodos de 0-14, 0-28 e 0-37 dias de avaliação, na fase de crescimento, em função dos níveis de lisina na ração para os dois grupos genéticos

Table 4 - Daily feed intake (DFI), daily gain weight (DGW), feed conversion (FC), lysine consumption (CL) from 0-14, 0-28 and 0-42 evaluation days, on growing phase, according to the dietary lysine levels for both genetic groups

\begin{tabular}{|c|c|c|c|c|c|c|c|c|c|c|c|c|}
\hline & \multicolumn{12}{|c|}{$\begin{array}{l}\text { Grupo genético } \\
\text { Genetic group }\end{array}$} \\
\hline & \multicolumn{6}{|c|}{$\begin{array}{l}\text { Comum } \\
\text { Common }\end{array}$} & \multicolumn{6}{|c|}{$\begin{array}{l}\text { Melhorado } \\
\text { Improved }\end{array}$} \\
\hline & \multicolumn{4}{|c|}{$\begin{array}{l}\text { Níveis de lisina }(\%) \\
\text { Levels of lysine }(\%)\end{array}$} & \multirow{2}{*}{$\begin{array}{l}\text { Média } \\
\text { Mean }\end{array}$} & \multicolumn{4}{|c|}{$\begin{array}{l}\text { Níveis de lisina (\%) } \\
\text { Levels of lysine (\%) }\end{array}$} & \multirow{2}{*}{$\begin{array}{l}\text { Média } \\
\text { Mean }\end{array}$} & \multirow{2}{*}{ CV $(\%)$} & \multirow{2}{*}{$\begin{array}{l}\text { Efeitos } \\
\text { Effects }\end{array}$} \\
\hline & 0,75 & 0,90 & 1,05 & 1,20 & & 0,75 & 0,90 & 1,05 & 1,20 & & & \\
\hline $\begin{array}{l}\text { Peso inicial }(\mathrm{kg}) \\
\text { Initial weight }(\mathrm{kg})\end{array}$ & 19,88 & 19,83 & 19,90 & 18,53 & 19,53 & 24,08 & 24,15 & 24,53 & 24,08 & 24,21 & & \\
\hline $\begin{array}{l}\text { Período 0-14 dias } \\
\text { Period 0-14 days }\end{array}$ & & & & & & & & & & & & \\
\hline $\begin{array}{l}\mathrm{CRD}(D F I), \mathrm{kg} \\
\mathrm{GPD}(D G W), \mathrm{kg} \\
\mathrm{CA}(F C) \\
\mathrm{CL}(L C), \mathrm{g} / \mathrm{dia}\end{array}$ & $\begin{array}{l}1,636 \\
0,764 \\
2,141 \\
12,27\end{array}$ & $\begin{array}{l}1,629 \\
0,659 \\
2,528 \\
14,66\end{array}$ & $\begin{array}{l}1,620 \\
0,766 \\
2,114 \\
17,01\end{array}$ & $\begin{array}{l}1,629 \\
0,738 \\
2,212 \\
19,54\end{array}$ & $\begin{array}{l}1,628 \\
0,731 \\
2,248 \\
15,87\end{array}$ & $\begin{array}{l}1,563 \\
0,700 \\
2,232 \\
11,72\end{array}$ & $\begin{array}{l}1,634 \\
0,786 \\
2,080 \\
14,70\end{array}$ & $\begin{array}{l}1,730 \\
0,841 \\
2,058 \\
18,16\end{array}$ & $\begin{array}{l}1,416 \\
0,613 \\
2,326 \\
16,99\end{array}$ & $\begin{array}{l}1,585 \\
0,735 \\
2,174 \\
15,39\end{array}$ & $\begin{array}{c}6,18 \\
11,90 \\
10,20 \\
-\end{array}$ & $\begin{array}{c}1 \\
1 \\
\mathrm{NS} \\
-\end{array}$ \\
\hline $\begin{array}{l}\text { Período 0-28 dias } \\
\text { Period 0-28 days }\end{array}$ & & & & & & & & & & & & \\
\hline $\begin{array}{l}\mathrm{CRD}(D F I), \mathrm{kg} \\
\mathrm{GPD}(D G W), \mathrm{kg} \\
\mathrm{CA}(F C) \\
\mathrm{CL}(L C), \mathrm{g} / \mathrm{dia} \\
\end{array}$ & $\begin{array}{l}1,914 \\
0,820 \\
2,336 \\
14,35 \\
\end{array}$ & $\begin{array}{l}1,824 \\
0,750 \\
2,431 \\
16,41 \\
\end{array}$ & $\begin{array}{l}1,826 \\
0,796 \\
2,292 \\
19,17 \\
\end{array}$ & $\begin{array}{l}1,843 \\
0,776 \\
2,380 \\
22,12 \\
\end{array}$ & $\begin{array}{l}1,851 \\
0,785 \\
2,359 \\
18,01\end{array}$ & $\begin{array}{l}1,732 \\
0,749 \\
2,315 \\
12,49 \\
\end{array}$ & $\begin{array}{l}1,784 \\
0,798 \\
2,237 \\
16,06\end{array}$ & $\begin{array}{l}1,940 \\
0,822 \\
2,355 \\
20,37 \\
\end{array}$ & $\begin{array}{l}1,540 \\
0,677 \\
2,287 \\
18,48\end{array}$ & $\begin{array}{l}1,749 \\
0,761 \\
2,298 \\
16,85\end{array}$ & $\begin{array}{l}8,32 \\
8,28 \\
4,64 \\
-\end{array}$ & $\begin{array}{c}2 \\
2 \\
\mathrm{NS} \\
-\end{array}$ \\
\hline $\begin{array}{l}\text { Período 0-37dias } \\
\text { Period 0-37 days }\end{array}$ & & & & & & & & & & & & \\
\hline $\begin{array}{l}\mathrm{CRD}(D F I), \mathrm{kg} \\
\mathrm{GPD}(D G W), \mathrm{kg} \\
\mathrm{CA}(F C) \\
\mathrm{CL}(L C), \mathrm{g} / \mathrm{dia}\end{array}$ & $\begin{array}{l}2,149 \\
0,892 \\
2,413 \\
16,11\end{array}$ & $\begin{array}{l}2,009 \\
0,791 \\
2,535 \\
18,08\end{array}$ & $\begin{array}{l}2,073 \\
0,822 \\
2,522 \\
21,76\end{array}$ & $\begin{array}{l}2,044 \\
0,836 \\
2,456 \\
24,53\end{array}$ & $\begin{array}{l}2,068 \\
0,835 \\
2,481 \\
20,12\end{array}$ & $\begin{array}{l}1,845 \\
0,752 \\
2,456 \\
13,84\end{array}$ & $\begin{array}{l}1,913 \\
0,820 \\
2,333 \\
17,22\end{array}$ & $\begin{array}{l}2,106 \\
0,846 \\
2,490 \\
22,11\end{array}$ & $\begin{array}{l}1,687 \\
0,725 \\
2,328 \\
20,24\end{array}$ & $\begin{array}{l}1,887 \\
0,785 \\
2,401 \\
18,35\end{array}$ & $\begin{array}{l}9,40 \\
8,99 \\
5,25 \\
-\end{array}$ & $\begin{array}{l}\text { NS } \\
\text { NS } \\
\text { NS } \\
-\end{array}$ \\
\hline
\end{tabular}

vou efeito $(\mathrm{P}>0,05)$ dos níveis de lisina sobre o GPD. SOUZA et al. (1999), trabalhando com machos castrados de 30 a $60 \mathrm{~kg}$ de peso vivo e níveis de lisina, variando de 0,58 a $0,83 \%$, verificaram efeito linear crescente dos níveis de lisina sobre o ganho de peso. FRIESEN et al. (1994), trabalhando com marrãs de 34 a $55 \mathrm{~kg}$ de peso vivo e níveis de lisina digestível, variando de 0,54 a 1,04, também constataram melhora linear $(\mathrm{P}<0,01)$ no ganho de peso diário médio.

Os valores de lisina aqui reportados, para maior consumo de ração diário e maior ganho de peso diário nos períodos de 0 a 14 e 0 a 28 dias de avaliação, para os animais do GGM, foram iguais aos valores recomendados pelo NRC (1998), para animais com peso vivo entre 20 e $50 \mathrm{~kg}$. Da mesma forma, foram similares ao valor de $0,93 \%$ de lisina, encontrado por BENATTI(1996), para animais na fase de crescimento, em trabalho de compilação de dados nutricionais praticados por dez empresas brasileiras que atuam no mercado de nutrição animal. Entretanto, no período de 0-37 dias de avaliação, os níveis de lisina não influenciaram $(\mathrm{P}>0,05)$ o $\mathrm{CRD}$, o que está de acordo com os resultados obtidos por DONZELE et al. (1994a), FRIESEN et al. (1994) e SOUZA et al. (1999).

Não houve efeito $(\mathrm{P}>0,05)$ dos níveis de lisina sobre a $\mathrm{CA}$, em nenhum dos períodos experimentais avaliados, para os animais do GGM, diferindo do resultado obtido por DONZELLE et al. (1994 b) que constataram efeito quadrático sobre a $\mathrm{CA}$, o que melhorou até $0,91 \%$ de lisina na ração. DONZELLE 
et al. (1994a) e SOUZA et al. (1999) obtiveram melhora linear na CA com o aumento dos níveis de lisina em até $0,89 \%$ e $0,83 \%$, respectivamente.

Não foram observadas diferenças $(\mathrm{P}>0,05)$ entre grupo genético, para as variáveis de desempenho, ou seja, as diferenças genéticas não foram suficientes para que pudessem expressar desempenho diferenciado.

$\mathrm{Na}$ Tabela 5 são apresentados os resultados da concentração do NUP, nos períodos de 14, 28 e 37 dias de avaliação na fase de crescimento, em função dos níveis de lisina na ração para os dois grupos genéticos.

Observou-se efeito quadrático $(\mathrm{P}<0,05)$ dos níveis de lisina sobre a concentração do NUP nos GGC e GGM, aos 14 dias de experimento, quando seriam observados menores valores de NUP quando a dieta contivesse $1,01 \%$ e $1,05 \%$ de lisina, segundo as equações $\mathrm{Y}=141,0590-274,2498 \mathrm{X}+$ $136,1111 \mathrm{X}^{2}\left(\mathrm{R}^{2}=0,36\right)$, e $\mathrm{Y}=136,6721-239,2500 \mathrm{X}$ $+113,8889 \mathrm{X}^{2}\left(\mathrm{R}^{2}=0,47\right)$, respectivamente. O mesmo comportamento foi obtido por COMA et al. (1995), que, trabalhando com suínos de 32 a $36 \mathrm{~kg}$ de peso vivo, obtiveram efeito quadrático dos níveis de lisina sobre a concentração de NUP, com menor nível em $0,85 \%$ de lisina na ração, portanto inferior àquele estimado no presente experimento.

Aos 28 e 37 dias de avaliação, os NUP nos animais do GGM, sofreram efeito $(\mathrm{P}<0,05)$ dos níveis de lisina. O NUP, aos 28 dias, apresentou comportamento quadrático, quando a menor concentração do NUP seria obtido quando a dieta contivesse $1,04 \%$ de lisina, indicando estar próximo da exigência nutricional de lisina do animal, de acordo com a equação $\mathrm{Y}=163,8245-300,0001 \mathrm{X}+$ $144,4445 X^{2}\left(R^{2}=0,56\right)$, ao passo que para o NUP, aos 37 dias, observou-se redução linear, segundo a equação $\mathrm{Y}=36,3749-19,1666 \mathrm{X}\left(\mathrm{R}^{2}=0,28\right)$. A redução do NUP é reflexo de uma melhor utilização no nitrogênio total da dieta, em função da diminuição da síntese de uréia, quando a exigência do primeiro aminoácido limitante foi atendida, ocorrendo uma minimização da excreção de uréia.

Não houve diferença $(\mathrm{P}>0,05)$ entre os grupos genéticos, para a variável NUP.

Os valores médios de espessura de toucinho no ponto $\mathrm{P}_{1}\left(\mathrm{ETP}_{1}\right)$, espessura de toucinho no ponto $\mathrm{P}_{2}$ $\left(\mathrm{ETP}_{2}\right)$, espessura de toucinho no ponto $\mathrm{P}_{3}\left(\mathrm{ETP}_{3}\right)$ e profundidade de lombo (PL), medidas nos animais vivos na fase de crescimento, aos 37 dias de avaliação, em função dos níveis de lisina nos dois grupos genéticos, são apresentados na Tabela 6 .

Analisando os resultados das medidas de características de carcaça obtidas através do aparelho Sono Grader, para os animais do GGM, observou-se efeito linear decrescente $(\mathrm{P}<0,05)$ dos níveis de lisina sobre $\mathrm{ETP}_{1}$ e PL de

Tabela 5 - Concentração do nitrogênio da uréia plasmática (NUP), nos períodos de 14, 28 e 37 dias de avaliação na fase de crescimento, em função dos níveis de lisina na ração para os dois grupos genéticos

Table 5 - Plasma urea nitrogen (PUN) concentration, during the periods of 14, 28 and 37 evaluation days on growing phase, according to the dietary lysine levels for both genetic groups

\begin{tabular}{|c|c|c|c|c|c|c|c|c|c|c|c|c|}
\hline & \multicolumn{12}{|c|}{$\begin{array}{c}\text { Grupo genético } \\
\text { Genetic group }\end{array}$} \\
\hline & \multicolumn{6}{|c|}{$\begin{array}{l}\text { Comum } \\
\text { Common }\end{array}$} & \multicolumn{6}{|c|}{$\begin{array}{l}\text { Melhorado } \\
\text { Improved }\end{array}$} \\
\hline & \multicolumn{4}{|c|}{$\begin{array}{l}\text { Níveis de lisina (\%) } \\
\text { Levels of lysine (\%) }\end{array}$} & \multirow{2}{*}{$\begin{array}{l}\text { Média } \\
\text { Mean }\end{array}$} & \multicolumn{4}{|c|}{$\begin{array}{l}\text { Níveis de lisina (\%) } \\
\text { Levels of lysine (\%) }\end{array}$} & \multirow{2}{*}{$\begin{array}{l}\text { Média } \\
\text { Mean }\end{array}$} & \multirow{2}{*}{$\mathrm{CV}(\%)$} & \multirow{2}{*}{$\begin{array}{l}\text { Efeitos } \\
\text { Effects }\end{array}$} \\
\hline & 0,75 & 0,90 & 1,05 & 1,20 & & 0,75 & 0,90 & 1,05 & 1,20 & & & \\
\hline $\begin{array}{l}\operatorname{NUP}(\mathrm{mg} / \mathrm{dl}) 14 \text { dias } \\
P U N(m g / d l) 14 \text { days }\end{array}$ & 19,50 & 15,00 & 9,25 & 17,00 & 15,18 & 22,25 & 12,00 & 13,25 & 13,25 & 15,18 & 31,82 & 1 \\
\hline $\begin{array}{l}\operatorname{NUP}(\mathrm{mg} / \mathrm{dl}) 28 \text { dias } \\
P U N(m g / d l) 28 \text { days }\end{array}$ & 16,00 & 11,50 & 8,50 & 10,50 & 11,62 & 19,50 & 8,75 & 8,25 & 10,50 & 11,75 & 40,35 & 2 \\
\hline $\begin{array}{l}\operatorname{NUP}(\mathrm{mg} / \mathrm{dl}) 37 \text { dias } \\
P U N(\mathrm{mg} / \mathrm{dl}) 37 \text { days }\end{array}$ & 21,25 & 18,00 & 17,25 & 20,50 & 19,25 & 23,00 & 18,50 & 14,50 & 14,75 & 17,68 & 28,64 & 3 \\
\hline
\end{tabular}

${ }^{1}$ Efeito quadrático $(P<0,05)$ dos níveis de lisina para os animais dos grupos genéticos comum e melhorado.

2 Efeito quadrático $(\mathrm{P}<0,05)$ dos níveis de lisina para os animais do grupo genético melhorado.

3 Efeito linear $(P<0,05)$ dos níveis de lisina para os animais do grupo genético melhorado.

$\mathrm{CV}=$ Coeficiente de variação (\%).

1 Quadratic effect $(P<0.05)$ of lysine levels for animals from genetic common and improved groups.

2 Quadratic effect $(P<0.05)$ of lysine levels for animals from improved genetic group.

3 Linear effect $(P<0.05)$ of lysine levels for animals from improved genetic group.

$C V=$ Coefficient of variation (\%).

Rev. bras. zootec., 30(6):1742-1749, 2001 
Tabela 6 - Valores médios da espessura de toucinho no ponto $P_{1}\left(E T P_{1}\right)$, espessura de toucinho do ponto $P_{2}\left(E T P_{2}\right)$, profundidade de lombo $(P L)$ e espessura de toucinho no ponto $P_{3}\left(E T P_{3}\right)$ no final da fase de crescimento, em função dos níveis de lisina na ração, para os dois grupos genéticos

Table 6 - Fat thickness average values at point $P_{1}\left(F T P_{1}\right)$, fat thickness at point $P_{2}\left(F T P_{2}\right)$, loin depth $(L D)$ and fat thickness at point $P_{3}$ $\left(F P_{3}\right)$ at the end of growing phase, according to the dietary lysine levels, for both genetic groups

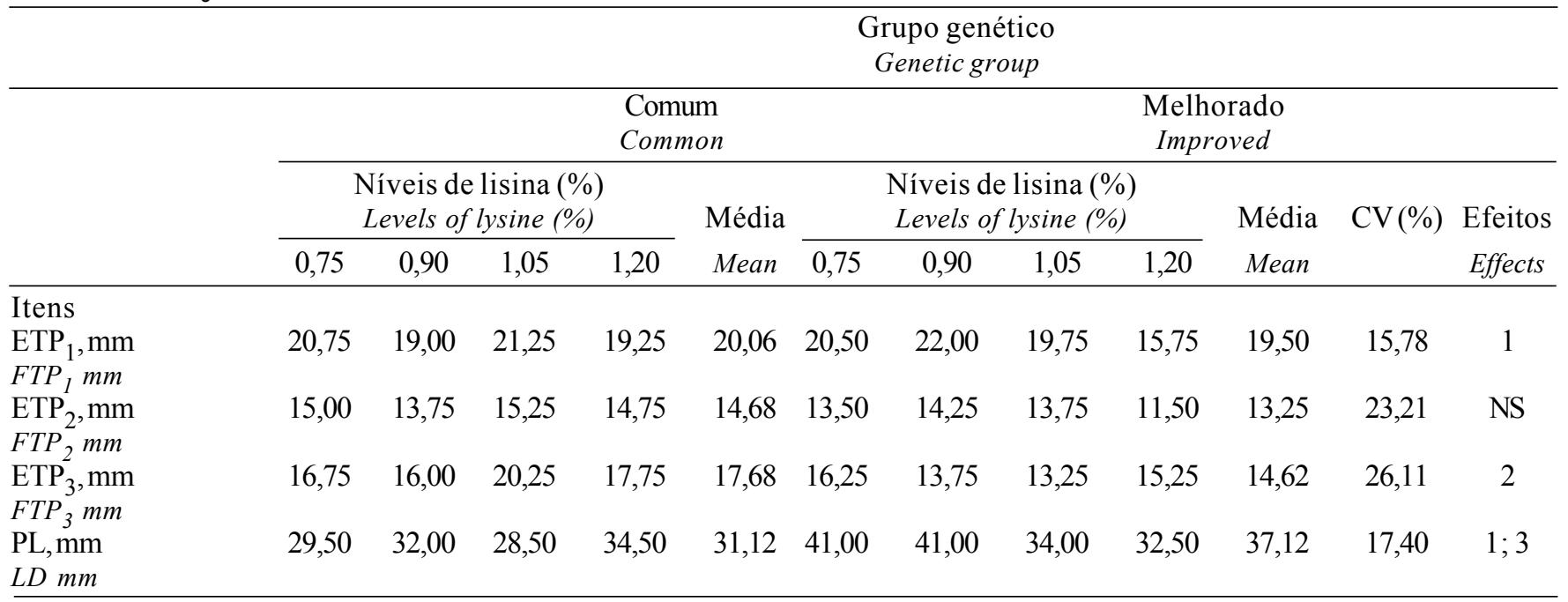

1 Efeito linear $(P<0,05)$ para os animais do grupo genético melhorado (Linear effect $[P<0.05]$ for improved genetic group animals).

2 Efeito entre grupo genético $(P=0,045)$ (Effect of genetic group $[P=0.045]$ ).

3 Efeito entre grupo genético $(P=0,038)$ (Effect of genetic group [P=0.038]).

$\mathrm{CV}=$ Coeficiente de variação $(\%)(C V=$ Coefficient of variation [\%])

acordo com as equações $\mathrm{Y}=30,225-11,0 \mathrm{X}\left(\mathrm{R}^{2}=0,20\right)$, e $\mathrm{Y}=58,2503-21,667 \mathrm{X}\left(\mathrm{R}^{2}=0,28\right)$, respectivamente.

Foram verificadas diferenças entre os grupos genéticos para $\mathrm{PL}(\mathrm{P}=0,038)$ e $\mathrm{ETP}_{3}(\mathrm{P}=0,045)$, onde o GGM apresentou maior PL e menor ETP ${ }_{3}$. Essa superioridade pode ser explicada em função do processo de seleção sofrido, visando melhorar as características de carcaça.

Fazendo uma análise conjunta dos resultados obtidos no experimento de desempenho e da variável nitrogênio da uréia plasmática, constatou-se que, nos períodos experimentais de 0-14 e 0-28 dias de avaliação, os níveis de exigência de lisina para suínos machos castrados do GGM de 24 a $34 \mathrm{~kg}$ e 34 a $45 \mathrm{~kg}$ de peso vivo estão entre 0,95 a 1,05\% e 0,95 a 1,04\%, respectivamente, para rações com baixo nível de proteína bruta (12 a 13,4\% $\mathrm{PB}$ ).

Para os suínos do GGC (20 a $50 \mathrm{~kg}$ de peso vivo), não houve melhoria nos resultados para níveis de lisina entre 0,75 e $1,20 \%$.

\section{Conclusões}

A exigência de lisina total, baseado no conceito de proteína ideal, para suínos machos castrados do GGM ( 24 a $45 \mathrm{~kg}$ de peso vivo) é de $1,00 \%$, enquanto para GGC (20 a $50 \mathrm{~kg}$ de peso vivo) é de $0,75 \%$.

\section{Agradecimento}

Em especial, à AJINOMOTO BIOLATINA Ind. e Comércio Ltda., pelo fornecimento dos aminoácidos, bem como pelas análises de aminoácidos.

\section{Referências Bibliográficas}

BAKER, D.H. 1993. Amino acid nutrition of pigs and poultry. In: Recent developments in pig nutricion 2. Loughborough Leicestershire Nottingham University Press. 375p.

BAKER, D.H. Advances in amino acid nutrition and metabolism of swine and poultry. In: KORNEGAY, E.T. Nutrient management of food animals to enhance and protect the environment. Boca Raton-FL CRC - Lewis Pub. p.41-53. 1996.

BENATI, M. Níveis nutricionais utilizados nas dietas de suínos. In: SIMPÓSIO INTERNACIONAL SOBRE EXIGÊNCIAS NUTRICIONAIS DE AVES E SUÍNOS, 1996, Viçosa. Anais...Viçosa, MG:UFV, 1996. p.447-457.

CAMPBELL, R.G. e TAVERNER, M.R. 1988. Genotype and sex effects on the relationship between energy intake and protein deposition for growing pigs. J. Anim. Sci., 66:676-686.

COMA, J. e ZIMMERMAN, D.R. 1993. Determination of lisina requeriment of growing pigs using plasma urea nitrogen in short-term trials. J. Anim. Sci., 71(Suppl. 1):60.

COMA, J., CARRION D., ZIMMERMAN, D.R. 1995. Use of plasma urea nitrogen as a rapid response criterion to determine the lysine requirement of pigs. J. Anim. Sci., 73(2):472-481.

CROMWELl, G.J., CLINE, T.R., CRENSHAW, J.D. et al. 1993. The dietary protein and (or) lysine requirements of barrows and gilt. J. Anim. Sci., 71(6):1510-1519. 
DONZELE, J.L., FREITAS, R.T.F., OLIVEIRA, R.F.M. et al. 1994a. Níveis de lisina para suínos machos inteiros dos 30 aos $60 \mathrm{~kg}$ de peso vivo. R. Soc. Bras. Zootec., 23(6):974-982.

DONZELE, J.L., FREITAS, R.T.F., OLIVEIRA, R.F.M. et al. 1994b. Níveis de lisina para leitoas de 30 a $60 \mathrm{~kg}$ de peso vivo. R. Bras. Zootec., 23(6):967-973.

EDMONDS, M.S., BAKER, D.H. 1987. Amino acid excesses for young pigs: effects of methionine, tryptophan, treonine or leucine. J. Anim. Sci., 64(6):1664-1671.

EMBRAPA. Centro Nacional de Pesquisa de Suínos e Aves (Concórdia- SC). 1991. Tabelas de composição química e valores energéticos de alimentos para suínos e aves. 3.ed. Concórdia. 97p. (EMBRAPA-CNPSA.Documentos, 19).

FERREIRA, A.S., PUPA, J.M.R. SOUZA, A.M. Exigências nutricionais para suínos determinadas no Brasil. In: SIMPÓSIO INTERNACIONAL SOBRE EXIGÊNCIAS NUTRICIONAIS DE AVES E SUÍNOS, 1996, Viçosa. Anais...Viçosa, MG:UFV, 1996. p.419-434.

FRIESEN, K.G, NELSSEN J.L., GOODBAND R.D. 1994. Influence of dietary lysine on growth and carcass composition of high-lean growth gilts fed from 34 to 72 kilograms. J. Anim. Sci., 72(7):1761-1770.

FRIESEN, K.G., TOKACH, M.D., NELSSEN, J.L. et al. 1996. A review of current amino acid estimates for swine-part I. Compêndio de educação continuada para o médico veterinário. Kansas State University, 18(8):35

GOODBAND, R.D., TOKACH, M.D., NELSSEN, J.L. 1994. Kansas swine nutrition guide. Kansas State University. 40p.

GOMES, S. et al. 1998. Responses of barrows consuming a diet formulated on an ideal protein basis at different feeding levels. Nebraska Swine Report. p.30-33.

HAHN, J.D, BIEHL, R.R., BAKER, D.H. 1995. Ideal digestible lysine level for early and late-finishing swine. J. Anim. Sci., 73(3):773-784.

HANSEN, B.C., LEWIS, A.J. 1993. Effects of dietary protein concentration on the performance and carcass characteristics of growing boars, barrows and gilts: mathematical descriptions. J. Anim. Sci., 71(8):2122-2132.
NACIONAL RESEARCH COUNCIL - NRC. 1998. Nutrient requirements of swine. 10.ed. Washington: National Academy of Science. 189p. (Nutrient Requirements of Domestic Animals, 2).

PARSONS, C.M., BAKER, D.H. The concept and use of ideal proteins in the feeding of nonruminants. In: SIMPÓSIO INTERNACIONAL DE PRODUÇÃO DE NÃO RUMINANTES, 1994, Maringá. Anais ... Maringá, 1994. p.119-128.

SILVA, D.J. 1990. Análise de alimentos: métodos químicos e biológicos. Viçosa: UFV. 165p.

SOUZA, A.M., ROSTAGNO, H.S., PUPA, J.M.R. et al. 1999. Exigências nutricionais de lisina para suínos mestiços, de 30 a $60 \mathrm{~kg}$ de peso. In: REUNIÃO ANUAL DA SOCIEDADE BRASILEIRA DE ZOOTECNIA, 36, 1999, Porto Alegre. Anais... Porto Alegre: UFRGS, 1999. p.227.

VAN LUNEN, T.A. 1995. Ideal protein requirements of modern genotypes. Pigs Misset., 12-13.

YEN, H.T., COLE, D.J.A., LEWIS, D. 1986. Amino acid requirements of growing pigs. 7. The response of pigs from 25 to $55 \mathrm{~kg}$ live weight to dietary ideal protein. Anim. Prod., 43(2):141-154.

Recebido em: 16/01/01

Aceito em: 31/05/01 